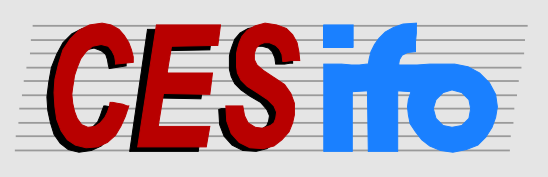

\title{
Working
}

Papers

www.cesifo.org/wp

\section{Development versus Legacy: The Relative Role of Development and Historical Legacies in Achieving Gender Equality}

\author{
Selin Dilli \\ Auke Rijpma \\ Sarah Carmichael
}

CESIFO WORKING PAPER NO. 4411

CATEgORY 3: Social PROTECTION

SEPTEMBER 2013

An electronic version of the paper may be downloaded

- from the SSRN website:

- from the RePEc website:

- from the CESifo website:

wWw.SSRN.com

www.RePEc.org

www.CESifo-group.org/wp

\section{CESifo}




\title{
Development versus Legacy: The Relative Role of Development and Historical Legacies in Achieving Gender Equality
}

\begin{abstract}
Economic development is often held to be beneficial for gender equality. However, there is good reason to believe that long lasting institutions like religion, legal traditions, and family practices, also matter. This paper provides an empirical assessment of the relative importance of development and historical determinants of gender equality at the cross-national level. To capture this long-term relationship, a new index of gender equality that stretches back to 1960 is introduced. Besides data on legal and religious traditions of countries, we also employ lesser known data on family systems in the analysis of the index. We find that variables on the long lasting institutions of countries can be as important as economic development in determining gender equality outcomes. Thus, our study highlights the importance of considering the contextual and historical conditions of a country when analysing the determinants of gender equality gaps.
\end{abstract}

JEL-Code: J120, J160, N000, Z130.

Keywords: gender, family systems, economic development, gender empowerment index.

\author{
Selin Dilli* \\ Utrecht University \\ Utrecht / The Netherlands \\ s.dilli@uu.nl
}

\author{
Auke Rijpma \\ Utrecht University \\ Utrecht / The Netherlands \\ a.rijpma@uu.nl
}

\author{
Sarah Carmichael* \\ Utrecht University \\ Utrecht / The Netherlands \\ s.g.carmichael@uu.nl
}

*corresponding authors

This version: June 2013 (preliminary version)

This project is made possible by http://www.clio-infra.eu/ and http://www.cgeh.nl/agencyproject. Attendance of the Venice summer Institute workshop was made possible by CESifo. 


\section{Introduction}

Much of the world is still characterised by gender inequality. Especially in developing countries, many women face limits to their freedom. They are discriminated against not just in the workplace and the political arena, but also within the household. This negatively affects women's decision making powers and sometimes even their survival chances. Besides the intrinsic importance of the well-being of women (Sen, 1999), the international development agenda also highlights the instrumental importance of women gaining an equal position to men (World Bank, 2011). However, there is still a lack of consensus on how to achieve this goal. The purpose of this paper is to provide an empirical assessment of the relative importance of economic development on the one hand and the persistent institutions of a country on the other in determining gender equality achievements. To achieve this, the paper will introduce new, long-term data on gender equality that will serve as the outcome for the empirical analysis.

Broadly speaking, the literature thus far has offered two sets of explanations for cross-national disparities in gender equality: modernization (development) and institutions (especially focusing on the informal institutions that shape the norms and values prevalent in a society). The modernization view argues that as countries become more economically developed, industrialized, democratic and their populations' more educated, equality between sexes will emerge, as the resources available to women will increase and give them a better bargaining position (Inglehart and Baker, 2000). An alternative mechanism through which modernization is expected to lead to gender equality is that it brings about shifts in the norms and values of societies which promote more gender egalitarian attitudes (Norris and Inglehart, 2003).

The strong correlation between income and gender inequality illustrated in figure 1 broadly supports the modernization view. However, this figure also points out some stark counterexamples to the correlation between development and gender equality. Most prominent are wealthy oil-producing states like Qatar and Saudi-Arabia that are nonetheless poor performers in measures of gender equality such as the UN's Gender Inequality Index or GII (UNDP, 2011). Other examples include China and India, countries which have achieved impressive rates 
of economic growth, but which have not made similar headway in the area of gender equality (Klasen and Wink, 2002). Even among the highly-developed countries of Europe, there are substantial differences in gender equality in regard to matters such as parental leave and labour force participation (Bruning and Plantenga, 1999). Not surprisingly then, one important conclusion in two recent reviews of research on gender inequality and development is that the link between economic development and gender equity is not automatic (Doepke et al., 2012; Duflo, 2012).

Figure 1. Gender equality versus economic development.

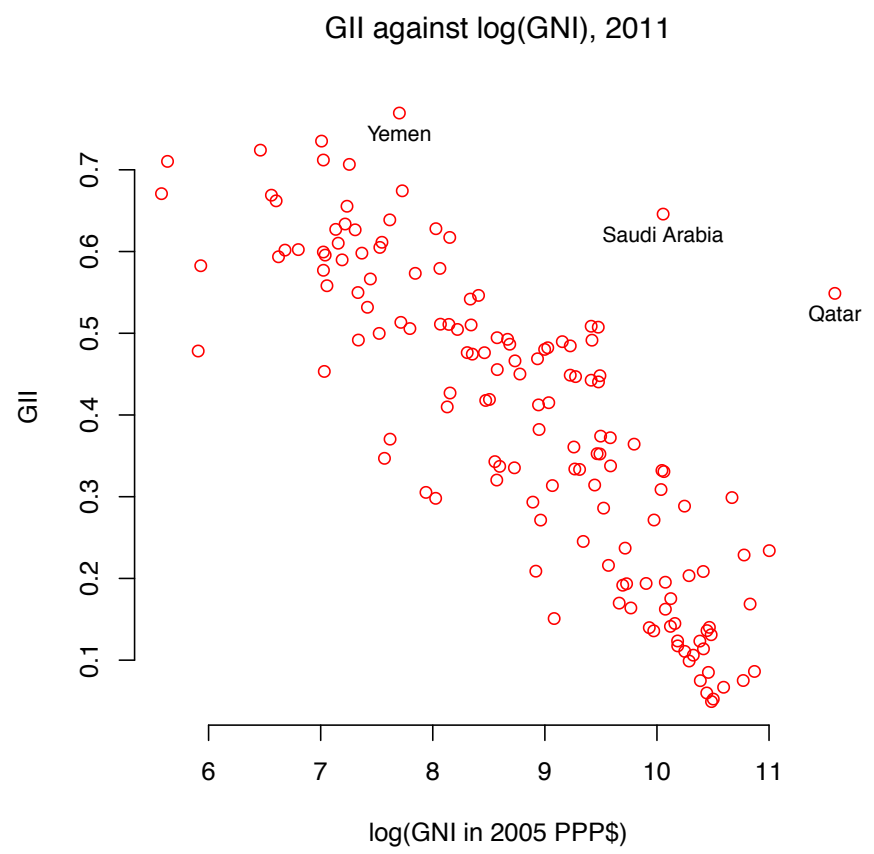

One explanation for these counterexamples lies in the role of longlasting institutions such as religion, family practices, and legal traditions that disadvantage women. This school of thought argues that, contrary to what would be expected from modernization theory, the norms and values of a society are persistent and are rooted in long lasting institutions, rather than merely lagging behind the development process (Alesina et al. 2013; Branisa et al. 2009; Branisa et al. 2013). For instance, the historical and cultural legacy of Islamic countries may be part of the explanation for what is observed in Saudi Arabia and Qatar (Spierings et al., 2009). Women are strongly disadvantaged by Islamic customs and laws concerning marital and inheritance practices (Weldon 
and Htun, 2012). Likewise, polygamy is a persistent family practice in sub-Saharan Africa and is associated with gender inequality (Bove and Vallegia, 2009; Tertilt, 2006).

Another example where economic development does not always translate to gender equality would be in the well-known case of the "missing women" (Sen, 1990). Klasen and Wink observe improvements in regard to this issue in some countries as their income and education levels improve. However, they also found that China and India actually experience worsening sex ratios despite their rapid economic growth. Part of this is a result of the rising availability of sex-selective abortion combined with a strong son preference in these countries, in turn associated with long-standing family systems (Klasen and Wink, 2002; Dyson and Moore, 1983).

The historical record too suggests that gender inequality is not solely determined by the level of development. For example, it has been observed that North-West European women had good access to labour markets well before the Industrial Revolution when the region was still poor by modern and even by contemporary international standards (De Moor and Van Zanden, 2010; Horrell and Humphries, 1995). Overall, these examples point to the fact that practices exist within given countries or across regions which disadvantage women and are unique and long-standing, probably going back centuries. These practices will not necessarily change quickly as a result of modernisation and/or economic development.

Our research shows that long-lasting institutions are important explanations of persistent variation in gender equality in addition to economic development. Although the development process betters the condition of women, long-lasting institutions are at least equal determinants of persistent gender inequalities.

The paper is organized as follows: Section II will discuss the views on the relationship between gender inequality and development, history and culture. In section III, we will introduce new, long-term data on gender inequality. Section IV discusses the operationalisation through family practices. Section $V$ will present the results and the final section concludes. 


\section{Literature}

Much of the literature on gender inequality suggests that as countries develop economically, we should expect gender inequality to decrease. In a recent review of the literature on women's empowerment and development, Esther Duflo (2012) concludes that the two are closely related. Indeed, there are many examples of studies that examine links from development to gender equality. For instance, Doepke et al. (2012) present a model where women's rights are determined by their returns to education, in turn largely driven by technological progress. Goldin (2006) argues that the growth in labour force participation by women in the USA between 1930 and 1950 was due to the increase in servicesector jobs. Another example of economic development leading to an increase in women's status is the decline in footbinding, a practice common in China until the early $20^{\text {th }}$ century, due to the transformation of textile production. Bossen et al. (2011) claim that as mass-produced textiles replaced domestic production, women's confinement to their home was questioned, as was the associated practice of footbinding. Finally, as an historical illustration of this link, Oster (2004) argues that witchcraft prosecutions in sixteenth and seventeenth-century Europe were caused by deteriorating economic conditions.

The idea that economic development will lead to gender equality fits with the modernization view. The proponents of this view argue that economic development leads to occupational specialization, rising educational levels, rising income levels, bringing about changes in gender roles, declining fertility rates and that all of this combined finally leads to increased gender equality (Inglehart and Baker, 2000). Modernization reduces the importance of biological differences between the sexes. For example, industrialization, machine technology, and the growth of the service sector decrease the importance of muscular strength and increases the value of intellectual skills, in which the two sexes are more equal. Higher income and education also lessens the need for numerous children, while modern medicine allows women to have greater control over reproduction. Therefore, women spend less of their lifetime bearing and rearing children (Christy, 1987). Another argument is that modernization is associated with more general cultural change. Cavalli (1983), for instance, observes that industrialization encourages egalitarian ideals, such as aspirations for more equality between two sexes and the idea that society should provide more egalitarian educational and occupational opportunities. Thus we expect that as 
countries become more socio-economically developed, gender inequalities will be lower (H1).

Although the modernization view suggests that development will bring about gender equality and cultural change, a growing body of literature claims that persistent norms, beliefs, and values matter. Inglehart and Baker (2000) highlight that cultural change depends on the heritages of societies and these heritages have autonomous and enduring effects ( $p$. 19). Hence, besides economic development, we would also expect that the values of a country or community matter for gender inequality. These long lasting institutions have to be studied alongside development to fully understand gender equality outcomes.

There are many examples in the empirical literature that confirm the notion that values matter. This applies to development outcomes in general as well as outcomes relating to gender equality. Nunn (2012) argues for the general importance of taking into account the values and beliefs of people when trying to explain the economic performance of countries. Branisa et al. (2013) also investigate the impact of social institutions on development outcomes. They find significant associations of long-lasting norms, values, and codes of conduct with gender inequality outcomes. In their study of missing women, Almond et al. (2013) find clear evidence that gender bias continues to exist among immigrants to Canada and can only be explained by taking into account their cultural background. In another paper, Alesina et al. (2013) demonstrate a relationship between traditional agricultural practices and present-day gender outcomes. More specifically, by analysing the children of immigrants they identify culture as a transmission mechanism.

From a historical, long-term perspective three types of institutions seem especially pertinent to us. First, traditions and practices regulating family life are especially important because families and households are a near-universal phenomenon. Moreover, these practices are very important to communities because they regulate their membership and transmit their values from one generation to the next (Shachar, 2001). One scholar who has looked at the importance of family ties is Reher (1998). He considers family ties persistent, historical systems, and observes their impact on present policy issues such as oldage care on a European wide scale. Likewise, Galasso and Profeta (2011) used a family system classification system devised by Emmanuel Todd to explain current day disparities within Europe in pension systems. In a 
similar vein, Duranton et. al (2009) suggest that family systems had an impact on regional disparities in many social and economic indicators in Europe. Finally, Alesina and Giuliano (2010) find that responses in the World Value Surveys indicating strong family ties significantly influence, amongst other things, female labour force participation, geographical mobility, and family size.

The second type of long-lasting cultural institution affecting gender outcomes is religion. For instance, controlling for the level of economic development, Donno and Russett (2012) found that the condition of women is significantly worse in Islamic countries than in others. Fish (2002) documents how Islam's poor treatment of women is responsible for the democratic deficit observed in many Islamic countries.

Third, the legal tradition of a country is another historical legacy that might influence gender equality. For instance, Weldon and Htun (2012) document that family law and the state-building histories in which they were crafted have a great influence on present-day gender equality outcomes. Related to this point is the work on legal origins stemming from the work by La Porta et al. $(1999,2008)$. Their concept of legal origins as an historically determined "style of social control of economic life (and maybe other aspects as well)" is very relevant for gender equality as well. Legal equality of men and women was an important step and educational reform, labour market access and health care priorities all required the sort of active government styles that La Porta et al. associate with civil and socialist law countries.

Thus we also expect that, in societies that are characterized by historical institutions regarding family, religion and legal traditions that are more supportive of the position of women, gender inequalities will be lower (H2).

Overall, the literature suggests that both development as well as the historical and cultural legacy of a country matter for achieving gender equality. An important question then becomes what the relative importance is of these two determinants of gender equality. The next sections will discuss the data and our method for answering this question. 


\section{Historical Development of Gender Equality}

In this section, we our measure of gender equality over the time period between 1960 and 2000, and describe the trends we observe in gender equality over time.

\section{III.a. Construction of Gender Equality Measure}

Previous studies that aim to measure gender equality point out the multidimensionality of the concept. Since the 1990s, measures that capture different aspects of gender equality simultaneously have become available such as the Gender Empowerment Measure (GEM) and the Gender Inequality Index (GII) by the UNDP, and the Social Institutions related to Gender Inequality (SIGI) database of the OECD.

Most of these measures are limited to the recent time period, focusing on gender development starting from the 1990s onwards. However, from the trends we observe in gender equality it emerges that women's struggle for equality with men is a long process. For example, the struggle of women for suffrage started at the end of the $19^{\text {th }}$ century, when in 1893 women gained the right to vote in New Zeeland, whereas Saudi Arabia remains as the only country in the world where women are still denied this right (Paxton et al., 2008). Similar long-term improvements can be observed in human capital formation, labour force participation and longevity indicators such as life expectancy which are crucial for women to gain an equal position to men (Dorius and Firebaugh, 2010). A historical perspective is required, not only to have a better grasp of the change in gender equality over time, but also to contribute to the understanding of the long term relationship between gender equality and development.

In an attempt to provide a long term perspective on the issue of gender inequality, Carmichael and Dilli (2014) in collaboration with the OECD present a historical gender equality measure. The information on the measures that have been used to capture different aspects of welfare related to gender equality is provided in table 1 below. The selection of these indicators is mostly based on the availability of the data. For more information on the conceptual and measurement issues related to index, please see Carmichael and Dilli (2014). ${ }^{2}$

\footnotetext{
2 The piece will become available in 2014 , but a technical note on the index is available upon request from the authors.
} 
Table 1. Overview of the measures in the Gender Equality Index

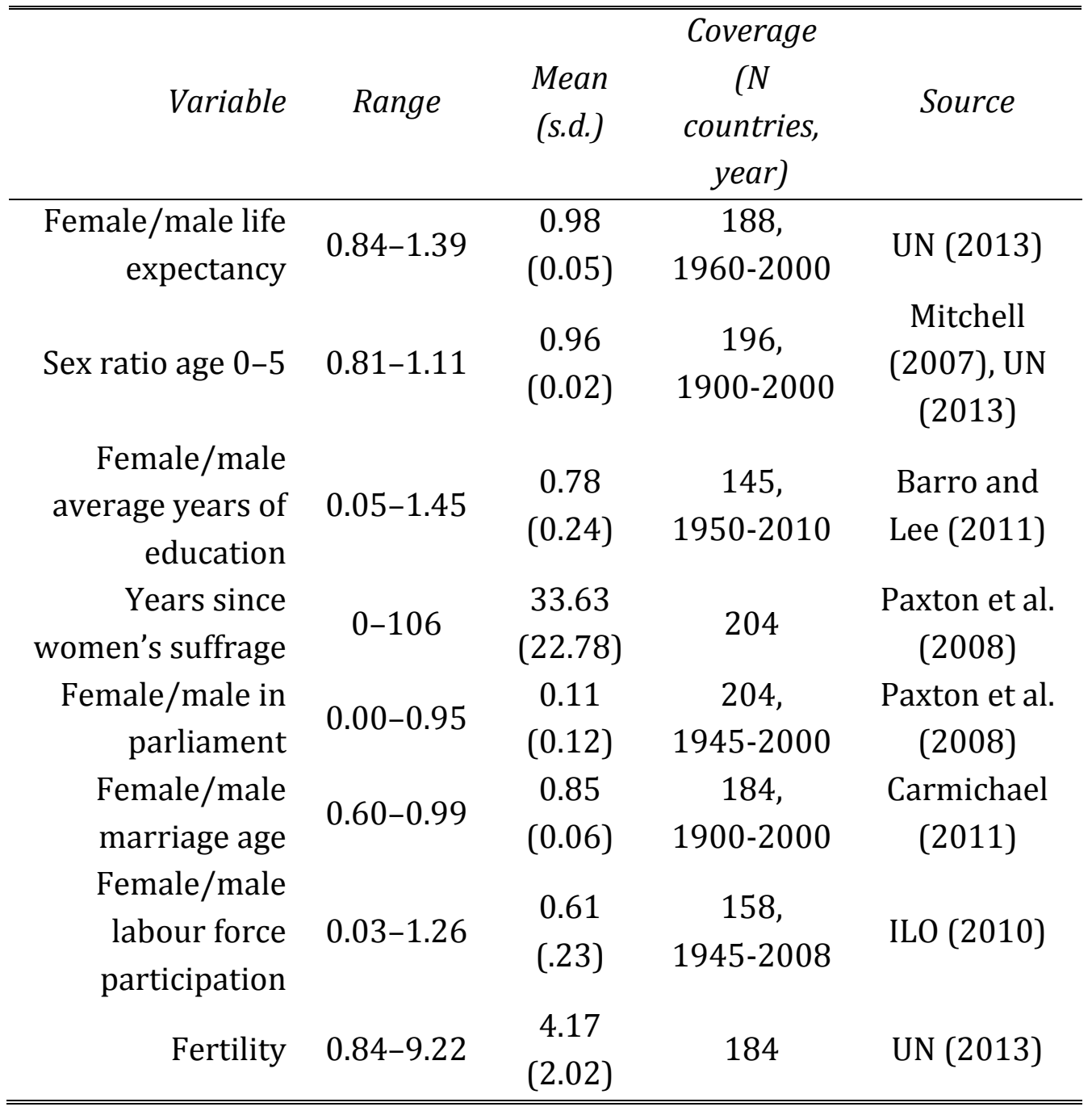

The overview provided in table 1 is based on non-imputed data. ${ }^{3}$ The data on life expectancy and the data coverage on the other indicators become substantially better after 1960 . Therefore, the historical gender equality index is limited to the time period between 1960 and 2000 . Nonetheless, this represents a substantial improvement over previous composite indices of gender equality. Whenever possible, the ratio between women and men is used to measure gender inequalities. Among our measures outlined in table 1, only fertility and the number of years women have had the right to vote are not in ratios. These two measures are converted to a similar range by taking the reciprocal of these two normalised measures. As we want a higher score to imply

\footnotetext{
3 To have the maximum country coverage in the index, missing data has been linearly interpolated based on time trend between 1960 and 2000.
} 
higher gender equality, the value obtained from the reciprocal of the number of years of suffrage was subtracted from one.

A principal component analysis of the various indicators reveals that all the items tap in a single dimension with an eigenvalue of 2.63. The scale has internal consistency with a Cronbach's alpha of 0.78 . In order to standardize our measure and eliminate the extreme scores of the countries, the variables are standardized by their maximum and minimum scores to a $0-1$ range. The arithmetic mean of these values was calculated by first taking the logarithm and exponential function of these values which was multiplied by $100 .{ }^{4}$ Our measure thus ranges between 0 and 100 where 100 is the highest score achievable using the highest attained values in the world. However, no country in our dataset has achieved a perfect score of 100 . In our index Sweden is the most gender egalitarian country with a score of 60.45 , while Iraq has the lowest score on the historical gender equality index with a score of 7.58.

III.b. Trends in Gender Equality

Figure 2. World average Gender Equality Index, 1960-2000.

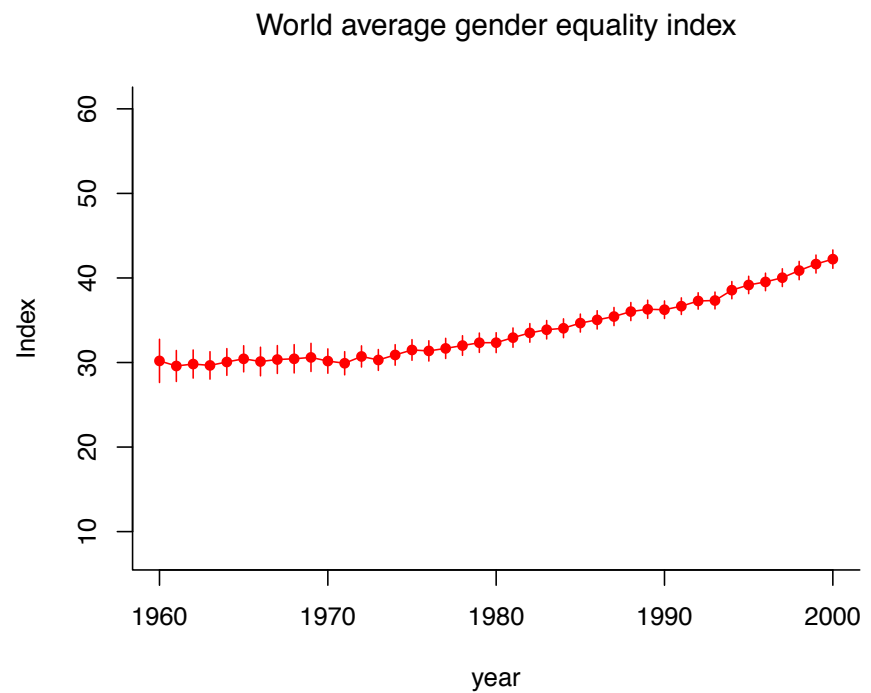

Figure 2 presents the overall results of the new measure in the form of an unweighted global average of country scores over the period 1960-

\footnotetext{
4 The arithmetic mean is an additive function, while the ratio is a multiplicative
} function. Therefore we use logarithms (Bericat, 2012). 
2000. The good news is that after a slow start in the 1960s, the gender equality measure exhibits a steady upward trend. After ca. 1980, the growth rate in gender equality is even seen to increase slightly. However, it should also be noted that global progress was limited. The global average in 2000 was still well short of the theoretical maximum of the index of one hundred. Looking at regional averages reveals further failings in achieving gender equality. It can be seen in figure 3 that the highest gender equality scores are largely found in Europe and its offshoots. Gender equality in other regions, particularly for the Middle East and North Africa (MENA), Sub-Saharan Africa and Southern Asia, was substantially lower.

Figure 3. Regional trends in the Gender Equality Index, 1960-2000.
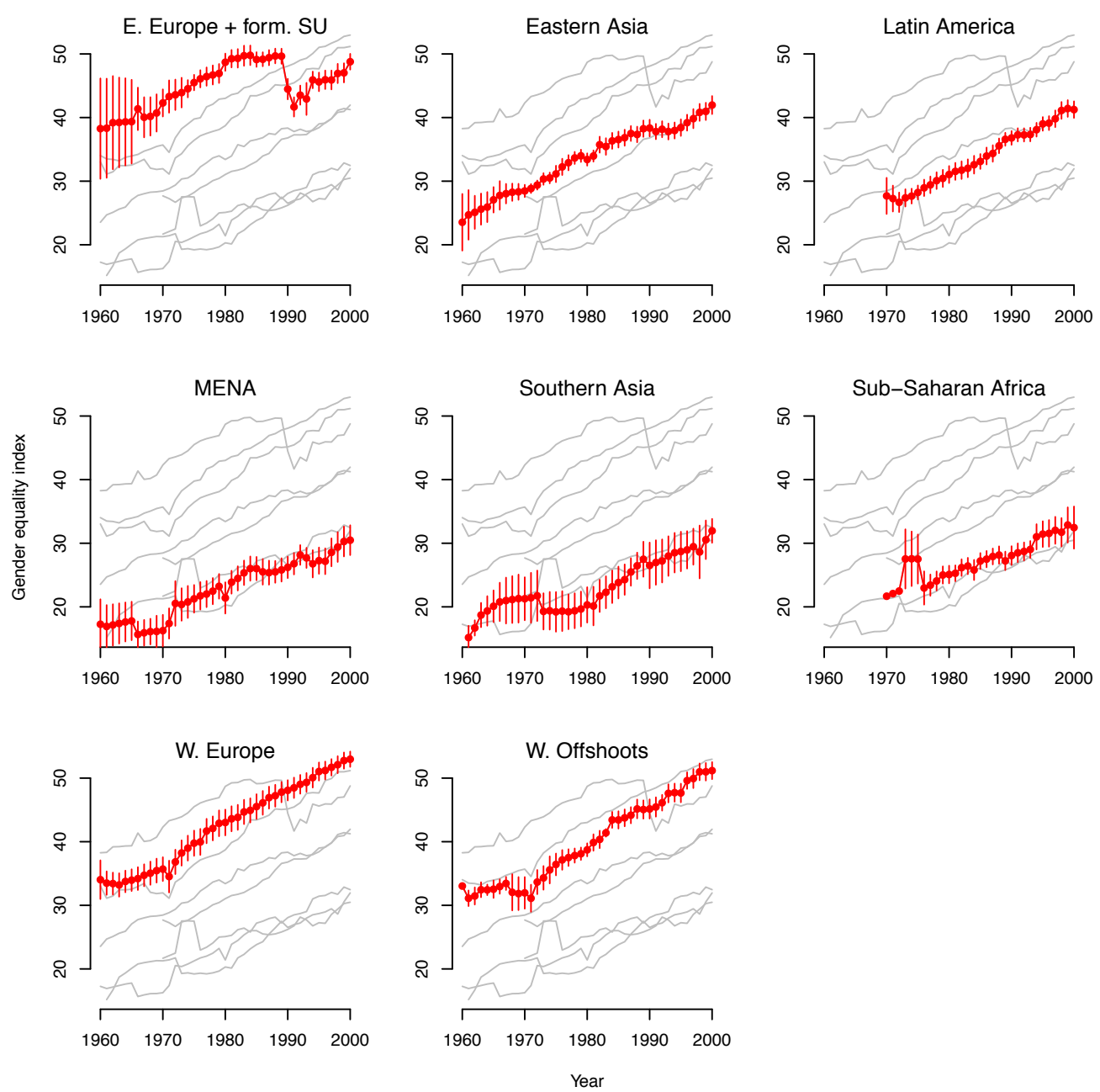

Figure 3 shows that there was progress in terms of gender equality everywhere, but there were nonetheless important differences between 
regions in the achievement of gender equality. The most striking observation is the reversal in the former communist countries of Eastern Europe and the Soviet-Union. After 1990, they had a strong decline in gender equality that lost them their top position. One explanation for this decline is related to the female representation in the parliaments of Eastern Europe which decreased markedly in the last two decade after the collapse of the Soviet Union. The East European countries which were once near the top in the world rankings of female representation are now far behind Northern Europe and even behind many Third World countries (Saxonberg 2000). Most progress was made in the Western Offshoots and Eastern Asia. Nonetheless, the overall picture is one of a persistent gap between the regions of the world. Poor performers like sub-Saharan Africa, Southern Asia, and the Middle East and North Africa are making some absolute progress in gender equality, but are not catching up to either the middle performers, Latin America and Eastern Asia, or top performers Europe and the Western Offshoots. Since the measure has an asymptotic limit of one hundred, this lack of convergence is all the more remarkable.

\section{Methodology}

Global data has been collected covering the time period between 1960 and 2000 to test the possible determinants of the gender equality outlined in the theory section. Our independent variables consist of two main groups: the long lasting (informal and formal) institutional factors and the political and economic characteristics of countries. The descriptive statistics of the variables are provided in table 2 .

To measure the long lasting institutions of societies, we focus on family systems (Todd, 1985), religion (Barro and McCleary, 2008) and legal origins (La Porta et al., 1999). All these variables are time invariant. Family systems is a categorical variable which classifies countries according to their egalitarianism in inheritance practices, the freedom they allow children in terms of spousal selection and coresidence practices. Using these dimensions, we make use of 7 categories: (1) egalitarian nuclear (reference category), (2) absolute nuclear, 3) stem, (4) endogamous community, (5) exogamous community, (6) anomic, (7) African families. More information on the operationalization of family systems can be found in table $A$ in the appendix. Our second variable, religion is measured as the percentage of 
the population that have Muslim, Protestant or Catholic religious denomination in 1970 which comes from Barro and McCleary (2008). ${ }^{5}$ As a measure of long lasting formal institutions determining the style of governance, we include the legal origins of the countries. The legal origins variable has four categories: (1) common law (reference category), (2) French civil law, (3) Socialist law, (4) Scandinavian/ German civil law. ${ }^{6}$

To capture the effect of economic characteristics on gender equality, we include log GDP per capita (Maddison, 2008) and total public spending on education as a percentage of GDP (Wejnert, 2007). ${ }^{7}$

We employ the Polity IV index (Marshall et al., 2011) to control for level of democracy in a country as democracy and gender equality are shown to be related (Inglehart et al., 2002). The Polity IV index scores countries on the quality of their democratic institutions. Concretely, it is based on three criteria: competitiveness of political participation, the competitiveness of executive recruitment, and constraints on the chief executive. The scale ranges from -10 (hereditary monarchy) to +10 (consolidated democracy). For ease of interpretation, the Polity IV index has been standardized to range between 0 and 1 in which a higher score means a higher level of democracy.

Finally, we include regional dummies to control for the effect of omitted regional characteristics, namely: (1) Eastern Asia, (2) Latin America, (3) Southern Asia, (4) Western Europe, 5) Sub-Saharan Africa 5) Western Offshoots 6) Eastern Europe and the (former) Soviet Union (reference category). ${ }^{8}$

\footnotetext{
5 The results are similar where religion is included in the analysis as a categorical measure where countries are classified as Muslim, Catholic and Protestant.

${ }^{6}$ Next to the institutional variables described above, the effect of colonial origin on gender equality has been tested. As the effect of colonial origin on gender equality is not consistent, this variable was dropped from the analysis.

7 We also tested for the effect of urbanization, the size of the workforce employed in the industrial and service sectors. Because these variables were highly correlated with GDP, inclusion of these variables did not provide additional information related to the role of socio-economic development on gender equality. Furthermore, the effect of oil rents as a percentage of GDP was tested which turned out to be insignificant. ${ }^{8}$ Although Sub-Saharan is highly correlated with the African family system, we keep this regional control in the analysis as inclusion of this variable does not change the interpretation of the other variables in the regression analysis.
} 
Table 2. Descriptive statistics $(N=106, n=2452)$

\begin{tabular}{|c|c|c|}
\hline Variable & Range & Mean (sd) \\
\hline Gender equality index & $7.58-60.46$ & $35.08(10.27)$ \\
\hline African family & $0 / 1$ & $0.124(0.32)$ \\
\hline Anomic family & $0 / 1$ & $0.249(0.432)$ \\
\hline Absolute nuclear family & $0 / 1$ & $0.11(0.319)$ \\
\hline Egalitarian nuclear family & $0 / 1$ & $0.12(0.32)$ \\
\hline Authoritarian family & $0 / 1$ & $0.14(0.35)$ \\
\hline Endogamous community family & $0 / 1$ & $0.13(0.345)$ \\
\hline Exogamous community family & $0 / 1$ & $0.12(0.32)$ \\
\hline Protestant70 & $0-0.97$ & $0.14(0.25)$ \\
\hline Catholic70 & $0-0.97$ & $0.36(0.375)$ \\
\hline Muslim70 & $0-1$ & $0.17(0.32)$ \\
\hline English Common Law & $0 / 1$ & $0.28(0.45)$ \\
\hline French C. Code & $0 / 1$ & $0.47(0.50)$ \\
\hline Socialist/Communist Laws & $0 / 1$ & $0.12(0.33)$ \\
\hline German/Scandinavian C. Code & $0 / 1$ & $0.13(0.33)$ \\
\hline $\log$ GDPPC & $6.00-10.26$ & $8.33(1.04)$ \\
\hline \% Education expenditures & $0.44-13.04$ & $4.45(1.84)$ \\
\hline Polity IV & $0-1$ & $0.64(0.374)$ \\
\hline E. Europe+ form. SU & $0 / 1$ & $0.08(0.27)$ \\
\hline Eastern Asia & $0 / 1$ & $0.12(0.32)$ \\
\hline Latin America & $0 / 1$ & $0.20(0.40)$ \\
\hline Middle East & $0 / 1$ & $0.10(0.31)$ \\
\hline Southern Asia & $0 / 1$ & $0.07(0.271)$ \\
\hline Sub-Saharan Africa & $0 / 1$ & $0.14(.34)$ \\
\hline W. Europe & $0 / 1$ & $0.23(0.42)$ \\
\hline W. Offshoots & $0 / 1$ & $0.06(0.24)$ \\
\hline
\end{tabular}

IV.a. Estimation Strategy

A first look at the bivariate relation between our independent variables and gender equality index is provided in the Spearman's correlation matrix in table $\mathrm{B}$ in the appendix.

The effect of institutions and development on gender equality is studied in a systematic manner by using the following panel data specification: 


$$
G_{i t}=\alpha+\beta_{k} Z_{i}+\beta_{l} X_{i t}+\beta_{m} \vartheta_{t}+\varepsilon_{i t}
$$

$G$ is the gender equality at time $t$ for country $i, \alpha$ is the constant, $Z$ represents the time-invariant institutional characteristics for country $i$, whereas $X$ represents the time-varying economic and political characteristics for country $i$ at time $t$. $\vartheta$ represents the year variable which is included to capture the long-term growth in gender equality and $\varepsilon$ is the error term. To estimate the model, pooled OLS is used (table 3). Equation (1) is estimated in four separate models. The first model includes only family systems, the second model includes the other timeinvariant institutional variables, the third model takes into account time varying economic and political characteristics and in the fourth model regional dummies are also included.

Next to the panel specification, the robustness of our findings are tested in two cross-sectional specifications. In model 5 an alternative gender equality measure is employed as the dependent variable. For this we used the Gender Inequality Index (GII) from the UNDP (2011) for 1995. It gives an indication of the inequality between men and women, measured along health, empowerment and labour market participation dimensions. The index ranges between 0 and 1 and a higher score implies higher gender inequality. In Model 6, we make use of our measure at time point 1995 to compare our results compared to the previous models. Our measure has a correlation of 0.84 points with the GII in 1995.

\section{Results}

The results of the first model show that countries that are characterized by family systems that are not favourable to women and promote authoritarian values also have higher gender inequality. Compared to egalitarian nuclear families, we find more gender inequality in countries with African family systems, characterised by a tradition of polygamy; in countries with endogamous community family systems emphasising large households and the bonds between brothers; and in countries with anomic family systems. To illustrate the difference, a country which is characterized by endogamous community families is expected to score 15.27 points less on the gender equality scale compared to a country characterised by an egalitarian nuclear family system, which is a substantial difference. Absolute nuclear families seem to score 6.06 points 
higher, whereas countries characterised by authoritarian family structures score 4.59 points higher on the gender equality scale compared to egalitarian nuclear families which implies that countries such as England, United States (absolute nuclear) and Germany and Norway (authoritarian) are expected to have higher gender equality than France and Portugal. This finding is not surprising considering that countries with absolute nuclear family systems do not have different family practices based on gender, but focus on individualism whereas egalitarian nuclear families accept the inequality of the sexes as a general norm. The difference between authoritarian and egalitarian nuclear family systems likely stems from the fact that female heirs are quite common in the former type of family. This finding is also in line with the study of Mamadough (1999) who argues that the status of women is higher in authoritarian family systems than in the nuclear family structure. Furthermore in line with what has been presented related to the development of gender equality over time in section 3, there is a significant effect of the time trend on gender equality.

In the second model, other institutional characteristics are included to see if family systems are indeed the cause of the variation in gender equality or whether it is related to other institutional characteristics of societies which are captured by family systems in model 1 . The results of model 2 show that once the differences in legal structure and religion are taken into account, countries that are characterized by absolute nuclear and authoritarian family structure are not significantly more gender egalitarian compared to egalitarian nuclear families. Looking at religion, countries that have a higher percentage of the population that have Protestant and Catholic as their religious denomination have significantly higher gender equality, whereas the opposite is true for the Muslim religious denomination. As for the legal origins variables, countries with socialist laws also score 10.13 points higher on the gender equality index. This is not surprising considering the experience of Soviet countries where gender equality was achieved in various dimensions by active policy implementation (Schalkwyk and Woroniuk, 1999; Weldon and Htun, 2012). At the same time, it is clear that family systems are still a meaningful explanation for explaining the differences in the gender equality index.

In the third model, more measures capturing development are included in the model. Though the effects have weakened, the results indicate that family systems, religion and legal origins are still meaningful sources of explanation for gender equality. This shows the importance of 
taking the role of informal and formal institutions into account when trying to explain gender equality. An important exception is that the results indicate that differences between anomic, African and egalitarian nuclear family types can be attributed to socio-economic and political differences. As to the effects of the development variables themselves, a one per cent increase in GDP per capita leads to a 3.95 point increase on the gender equality index, whereas the percentage of GDP spent on education does not have a significant effect on gender equality. Looking at the difference in the $\mathrm{R}^{2}$ between model 2 and 3 shows that institutional characteristics explain a substantial share of the variation in the gender equality index.

In the fourth model we include regional fixed effects in the model. Doing so has no substantial impact on the religion and legal origins variables, but does makes the significant differences between family systems disappear. One plausible explanation is the high correlation between the family systems and regional dummies. To check the robustness of this finding, we employed data reconstructing on the underlying variables of Todd's family systems by means of Murdock's (1967) Ethnographic Atlas which makes up the classification of Todd's family systems (Bolt, 2012). However, the results were similar to the ones presented in model 4: once the regional differences are taken into account, differences in the household structure (nuclear versus extended), inheritance practices (partible versus impartible) and choice of marriage partner (endogamy versus exogamy) are not associated with different gender equality outcomes.

Lastly, in model 5 and model 6, the robustness of our findings are checked in two cross sectional specifications. The conclusions that can be drawn from these two models are similar to the ones discussed above. The only difference when using the GII is related to the effect of religion. When using our own gender measure of gender inequality, Muslim and Protestant religious denominations explain more, whereas the Catholic religious denomination explains more in the GII index. This finding is likely to be the result of different dimensions captured in the two indices. The main differences between our index and the GII is that we also include sex ratios, life expectancies and marriage ages to capture gender inequality. 
Table 3. Results for OLS regressions of gender equality, 1960-2000.

\begin{tabular}{|c|c|c|c|c|c|c|}
\hline & (1) & (2) & (3) & $(4)$ & \multirow{3}{*}{$\begin{array}{c}\text { (5) } \\
\text { GII } \\
1995\end{array}$} & (6) \\
\hline & \multicolumn{4}{|c|}{ Gender equality index } & & $\mathrm{GEI}^{\wedge}$ \\
\hline & \multicolumn{4}{|c|}{ (1960-2000) } & & 1995 \\
\hline \multirow{2}{*}{ African family } & $-10.55^{*}$ & $-7.93^{*}$ & -0.91 & 1.86 & -0.05 & 2.71 \\
\hline & $(2.07)$ & $(1.78)$ & $(1.96)$ & $(2.65)$ & $(0.04)$ & $(2.14)$ \\
\hline \multirow{2}{*}{ Anomic family } & $-5.22^{*}$ & $-4.00^{*}$ & -1.19 & -0.86 & $0.05+$ & 0.21 \\
\hline & (1.69) & $(1.45)$ & $(1.22)$ & $(1.47)$ & $(0.03)$ & $(2.06)$ \\
\hline \multirow{2}{*}{$\begin{array}{r}\text { Absolute nuclear } \\
\text { family }\end{array}$} & $6.06^{*}$ & 0.06 & -2.80 & -2.99 & -0.00 & -3.62 \\
\hline & $(2.04)$ & $(2.47)$ & $(1.95)$ & $(2.36)$ & $(0.05)$ & $(3.86)$ \\
\hline \multirow{2}{*}{ Authoritarian family } & $4.59+$ & 1.03 & -1.50 & -2.04 & 0.01 & -0.75 \\
\hline & $(2.60)$ & $(2.13)$ & $(1.70)$ & $(1.44)$ & $(0.03)$ & $(1.74)$ \\
\hline Endogamous & $-15.27^{*}$ & $-7.11^{*}$ & $-4.00+$ & -2.62 & 0.04 & 0.89 \\
\hline community family & $(1.93)$ & $(2.79)$ & $(2.42)$ & $(2.34)$ & $(0.05)$ & $(3.44)$ \\
\hline Exogamous & 1.57 & -3.60 & -1.09 & -0.38 & 0.02 & 1.17 \\
\hline community family & $(4.47)$ & $(2.47)$ & $(1.52)$ & $(1.56)$ & $(0.03)$ & $(1.76)$ \\
\hline \multirow{2}{*}{ Year } & $0.48^{*}$ & $0.45^{*}$ & $0.35^{*}$ & $0.38^{*}$ & & \\
\hline & $(0.04)$ & $(0.03)$ & $(0.03)$ & $(0.03)$ & & \\
\hline \multirow{2}{*}{ Muslim70 } & & $-5.90 *$ & $-5.48^{*}$ & $-5.85^{*}$ & 0.06 & $-9.25 *$ \\
\hline & & $(2.83)$ & $(2.16)$ & $(2.06)$ & $(0.05)$ & $(3.56)$ \\
\hline \multirow{2}{*}{ Prot70 } & & $17.50^{*}$ & $12.71 *$ & $12.32^{*}$ & -0.05 & $12.70^{*}$ \\
\hline & & $(3.40)$ & $(2.55)$ & $(2.53)$ & $(0.06)$ & $(4.12)$ \\
\hline \multirow{2}{*}{ Cath70 } & & $3.00+$ & 1.47 & $2.62+$ & $-0.08^{*}$ & 2.82 \\
\hline & & $(1.72)$ & (1.33) & $(1.49)$ & $(0.03)$ & $(2.24)$ \\
\hline Scandinavian/ & & 2.31 & 2.04 & 1.55 & -0.05 & -1.27 \\
\hline German C. code & & $(2.26)$ & $(1.72)$ & (1.75) & $(0.04)$ & $(3.06)$ \\
\hline \multirow{2}{*}{ French C. Code } & & 0.55 & -0.24 & -0.05 & 0.03 & -0.14 \\
\hline & & (1.33) & $(1.15)$ & $(1.10)$ & $(0.03)$ & (2.13) \\
\hline Socialist/ & & $10.13^{*}$ & $10.45^{*}$ & $10.35^{*}$ & $-0.10^{*}$ & $8.34^{*}$ \\
\hline Communist Laws & & $(2.06)$ & (1.14) & $(1.50)$ & $(0.04)$ & $(2.28)$ \\
\hline \multirow{2}{*}{$\log$ GDPPC } & & & $3.95^{*}$ & $3.37^{*}$ & $-0.12^{*}$ & $4.40^{*}$ \\
\hline & & & $(0.57)$ & $(0.59)$ & $(0.02)$ & $(1.07)$ \\
\hline \multirow{2}{*}{ Polity IV } & & & 0.69 & 0.44 & 0.05 & -1.36 \\
\hline & & & (1.10) & (1.15) & $(0.03)$ & $(2.57)$ \\
\hline$\%$ Education & & & 0.13 & 0.26 & -0.00 & -0.06 \\
\hline expenditures & & & $(0.23)$ & $(0.24)$ & $(0.01)$ & $(0.37)$ \\
\hline \multirow{2}{*}{ Eastern Asia } & & & & 2.61 & -0.06 & 0.82 \\
\hline & & & & (1.93) & $(0.05)$ & $(2.65)$ \\
\hline Latin America & & & & -0.86 & $0.08+$ & 0.63 \\
\hline
\end{tabular}




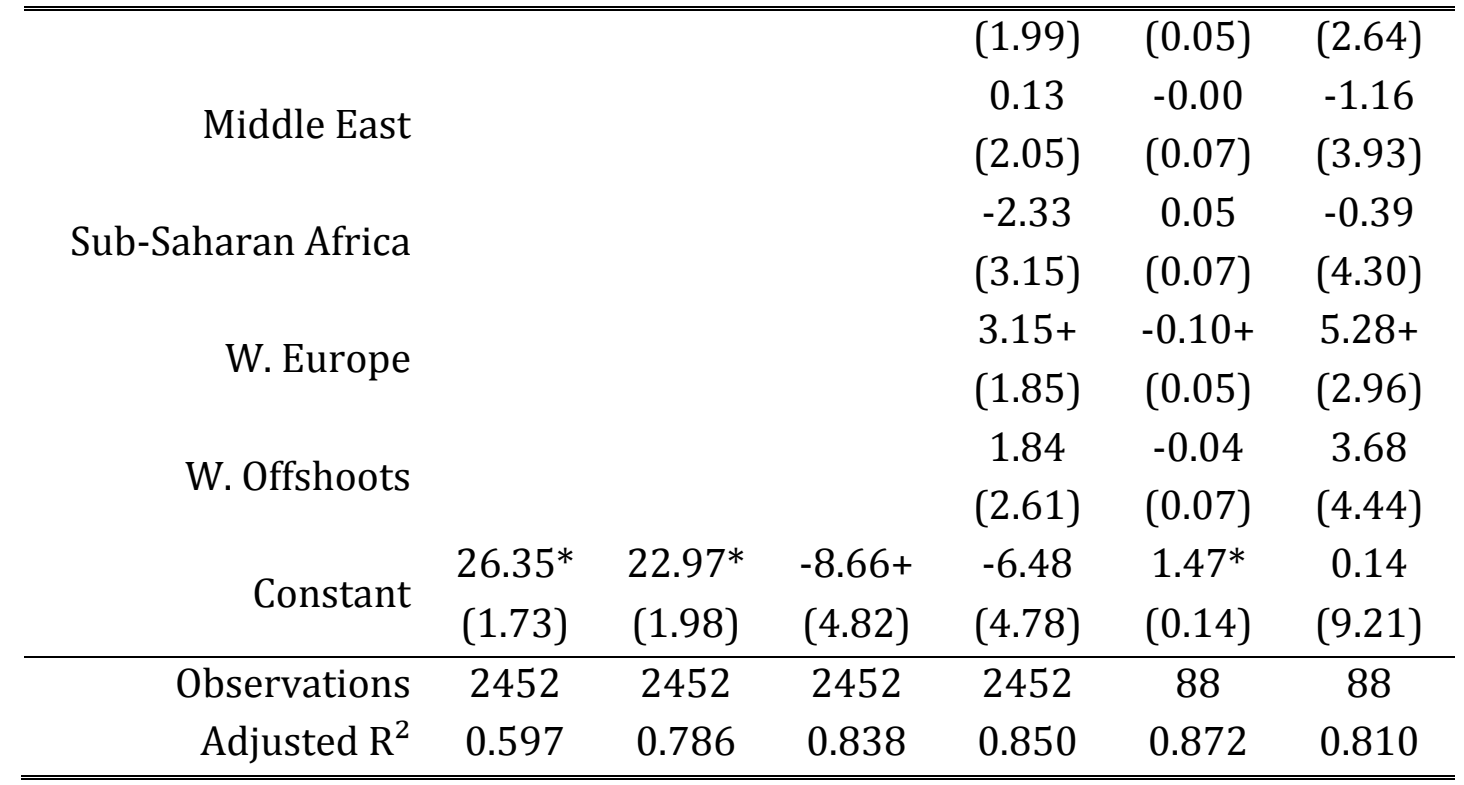

Notes: ${ }^{* *} p<.001,{ }^{* *} p<0.01,{ }^{*} p<0.05,+p<.10$ (for two-tailed-t test). Reference category for the family systems is egalitarian nuclear family. The unstandardized coefficients are reported with robust standard errors clustered by country in parenthesis.

^ In model 6, GEI refers to our historical gender equality index in 1995.

To judge the relative impact of the variables, we need to look at standardized coefficients. Table 4 reports these coefficients for the most complete model (4) and shows that development variables clearly matter for gender equality. For one, income has the largest effect among the explanatory variables. A one standard deviation increase in log GDP per capita is associated with a 0.34 standard deviation increase in the gender equality index.

However, we would like to emphasise that the institutional legacy of countries is as important for gender equality outcomes as development characteristics are. Socialist legal origins turn out to have a large positive impact (0.33 standard deviation) on gender equality in the period 1960-2000. The same holds for religion, with countries that have large share of Protestants showing standardized effects of a similar magnitude. 
Table 4. Standardized coefficients based on model 4.

\begin{tabular}{rc}
\hline \hline Variables & Beta Coefficients \\
\hline African family & 0.059 \\
Anomic family & -0.035 \\
Absolute nuclear family & -0.091 \\
Authoritarian family & -0.070 \\
Endogamous community family & -0.087 \\
Exogamous community family & -0.012 \\
Muslim70 & -0.184 \\
Prot70 & 0.302 \\
Cath70 & 0.099 \\
Scandinavian/German C. code & 0.050 \\
French C. Code & -0.002 \\
Socialist/Communist Laws & 0.328 \\
log GDPPC & 0.341 \\
Polity IV & 0.016 \\
\% Education expenditures & 0.047 \\
Eastern Asia & 0.083 \\
Latin America & -0.033 \\
Middle East & 0.004 \\
Sub-Saharan Africa & -0.078 \\
W. Europe & 0.128 \\
W. offshoots & 0.042 \\
Year & 0.376 \\
\hline
\end{tabular}

\section{Conclusion}

Over the past decades the idea that gender equality matters has steadily gained credence. The reasons for this are many, ranging from the intrinsic importance of treating women as equal to men, to "smart economics" - the idea that improving gender equality is beneficial for health outcomes for children or for increased economic growth due to higher female labour force participation (World Bank, 2011). Given the importance of achieving gender equality, we have set out in this paper to explore what causes cross-national differences in gender inequality outcomes over a forty year period (1960-2000).

The literature gives good reasons to believe that both development (modernization) and long-term, informal institutions could matter 
for gender equality. Because both are long-term developments, changes in gender equality should be analysed from a long-term perspective as well. To this end, we have employed a new index of gender equality spanning four decades. When comparing the effect of development and long-term institutions on the new index, we find that long-term informal institutions especially, religion, and legal systems are almost as important as economic development for gender equality outcomes.

These preliminary results illustrate how persistent gender gaps are determined by a range of different factors. Showing that both institutional and development characteristics play a role in determining gender equality outcomes, one link remains to be explored in our study: the interplay between these two factors. This would provide a better understanding of why countries that achieve economic development, such as China and India, still struggle to achieve gender equality. This is key to keep in mind when designing policy geared towards tackling gender inequality. The specific historical and cultural legacy of countries will mean that when it comes to reducing gender gaps there is no one size fits all policy, and that even when simply trying to understand why gender gaps persist a multifaceted approach must be taken. 


\section{Appendix}

Table A. Todd's Family Systems

\begin{tabular}{|c|c|c|c|}
\hline Family Type & $\begin{array}{l}\text { Attitudes to liberty (defined by } \\
\text { co-residence and type of spouse } \\
\text { selection) }\end{array}$ & $\begin{array}{l}\text { Attitudes to } \\
\text { symmetry } \\
\text { (defined by } \\
\text { inheritance) }\end{array}$ & Country Examples \\
\hline $\begin{array}{l}\text { Egalitarian nuclear } \\
\text { family }\end{array}$ & Free, with obligatory exogamy & Symmetry & $\begin{array}{l}\text { France, Switzerland, Poland, } \\
\text { Romania, Italy, Greece, Spain, } \\
\text { Portugal, partly Latin America }\end{array}$ \\
\hline $\begin{array}{l}\text { Exogamous } \\
\text { community family }\end{array}$ & Parents & Symmetry & $\begin{array}{l}\text { Russia, Yugoslavia, Slovakia, } \\
\text { Bulgaria, Hungary, Albania, China, } \\
\text { India and Cuba }\end{array}$ \\
\hline $\begin{array}{l}\text { Endogamous } \\
\text { Community Family }\end{array}$ & Custom & Symmetry & $\begin{array}{l}\text { Arab world, Turkey, Afghanistan, } \\
\text { Iran, Pakistan, Azerbaijan, } \\
\text { Turkmenistan, and Uzbekistan }\end{array}$ \\
\hline $\begin{array}{l}\text { Absolute Nuclear } \\
\text { Family }\end{array}$ & Free, with obligatory exogamy & Indifference & $\begin{array}{l}\text { United Kingdom, the United States, } \\
\text { Canada, New Zealand, Australia, } \\
\text { the Netherlands and Denmark }\end{array}$ \\
\hline Anomic Family & Free, without obligatory & Indifference & Burma, Thailand, Laos, Philippines, \\
\hline
\end{tabular}




\begin{tabular}{|c|c|c|c|}
\hline & exogamy & & $\begin{array}{l}\text { Cambodia, Malaysia, Indonesia, } \\
\text { Madagascar, Sri Lanka }\end{array}$ \\
\hline Stem Family & Parents & Asymmetry & $\begin{array}{l}\text { Germany, Austria, Belgium, } \\
\text { Norway, Sweden, Israel, Japan, and } \\
\text { Korea }\end{array}$ \\
\hline African Family & $\begin{array}{l}\text { Indifference, generally strong } \\
\text { prohibitions of consanguinity }\end{array}$ & Indifference & $\begin{array}{l}\text { All Africa except the Northern } \\
\text { African } \\
\text { countries and South Africa }\end{array}$ \\
\hline
\end{tabular}


Table B. Spearman's Correlation Matrix between Variables

\begin{tabular}{|c|c|c|c|c|c|c|c|c|c|c|c|c|c|c|c|c|c|c|c|c|c|c|c|}
\hline & 1 & 2 & 3 & 4 & 5 & 6 & 7 & 8 & 9 & 10 & 11 & 12 & 13 & 14 & 15 & 16 & 17 & 18 & 19 & 20 & 21 & 22 & 23 \\
\hline 1 & 1.00 & & & & & & & & & & & & & & & & & & & & & & \\
\hline 2 & -.35 & 1.00 & & & & & & & & & & & & & & & & & & & & & \\
\hline 3 & .36 & -.35 & 1.00 & & & & & & & & & & & & & & & & & & & & \\
\hline 4 & .33 & -.36 & -.14 & 1.00 & & & & & & & & & & & & & & & & & & & \\
\hline 5 & .45 & -.35 & -.14 & $.40^{*}$ & 1.00 & & & & & & & & & & & & & & & & & & \\
\hline 6 & .16 & .39 & -.10 & -.25 & .20 & 1.00 & & & & & & & & & & & & & & & & & \\
\hline 7 & -.46 & .07 & -.04 & -.30 & -.42 & -.55 & 1.00 & & & & & & & & & & & & & & & & \\
\hline 8 & -.21 & -.03 & -.14 & -.14 & .16 & -.04 & .19 & 1.00 & & & & & & & & & & & & & & & \\
\hline 9 & -.12 & 0.29 & -.09 & -.22 & -.07 & .34 & -.15 & -.20 & 1.00 & & & & & & & & & & & & & & \\
\hline 10 & .27 & -.22 & -.13 & .03 & .47 & .01 & -.10 & -.13 & -.19 & 1.00 & & & & & & & & & & & & & \\
\hline 11 & .26 & -.30 & -.09 & .64 & .20 & -.02 & -.25 & -.15 & -.23 & -.14 & 1.00 & & & & & & & & & & & & \\
\hline 12 & -.45 & .18 & -.05 & -.15 & -.46 & -.47 & .59 & -.14 & -.22 & -.14 & -.16 & 1.00 & & & & & & & & & & & \\
\hline 13 & .19 & -.34 & .50 & .02 & -.07 & -.24 & -.03 & -.13 & -.20 & -.13 & -.15 & -.14 & 1.00 & & & & & & & & & & \\
\hline 14 & .55 & -.27 & -.14 & .40 & .40 & .11 & -.39 & -.24 & -.14 & .43 & .42 & -.32 & -.03 & 1.00 & & & & & & & & & \\
\hline 15 & .43 & -.28 & .09 & 0.25 & .36 & -.05 & -.15 & -.01 & -.28 & .33 & .24 & -.06 & .04 & .39 & 1.00 & & & & & & & & \\
\hline 16 & .65 & -.13 & -.10 & .41 & .38 & .20 & -.43 & -.44 & -.18 & .45 & .42 & -.26 & -.11 & .68 & .46 & 1.00 & & & & & & & \\
\hline 17 & .01 & -.17 & -.11 & .15 & $-.11^{*}$ & -.24 & -.08 & -.14 & .37 & -.13 & .12 & -.15 & -.05 & -.13 & -.19 & -.08 & 1.00 & & & & & & \\
\hline 18 & -.05 & .47 & -.11 & -.19 & -.01 & .58 & -.45 & -.18 & .56 & -.17 & -.21 & -.20 & -.10 & -.10 & -.19 & -.05 & -.18 & 1.00 & & & & & \\
\hline 19 & -.34 & .22 & -.10 & -.12 & -.42 & -.34 & .48 & -.12 & -.19 & -.12 & -.03 & .75 & -.12 & -.24 & .09 & -.08 & -.13 & -.17 & 1.00 & & & & \\
\hline 20 & -.32 & -.25 & -.10 & -.11 & -.24 & -.28 & .26 & -.10 & -.03 & -.10 & -.11 & .16 & .30 & -.08 & -.30 & -.35 & -.10 & -.14 & -.09 & 1.00 & & & \\
\hline 21 & -.26 & .03 & -.15 & -.15 & .11 & -.07 & .26 & .92 & -.22 & -.13 & -.16 & -.07 & -.14 & -.29 & .02 & -.48 & -.15 & -.19 & -.14 & -.11 & 1.00 & & \\
\hline 22 & .39 & -.04 & -.20 & -.48 & .29 & .09 & -.25 & -.20 & -.30 & .18 & .42 & -.21 & -.06 & .51 & .24 & .60 & -.20 & -.26 & -.18 & -.15 & -.21 & 1.00 & \\
\hline 23 & 0.15 & -.24 & -.09 & -.10 & .32 & .05 & -.12 & -.09 & -.14 & .73 & -.10 & -.10 & -09 & .31 & .23 & .33 & -.09 & -.13 & -.09 & -.07 & -.10 & -.14 & 1.00 \\
\hline
\end{tabular}


Table B1. Key to Correlation Matrix

\begin{tabular}{rc}
\hline \hline 1 & Gender Equality \\
\hline 2 & French Legal Origin \\
3 & Socialist/Communist Legal Origin \\
4 & Scandinavian/ German Legal Origin \\
5 & Protestant \\
6 & Catholic \\
7 & Muslim \\
8 & African Family \\
9 & Anomic Family \\
10 & Absolute Nuclear Family \\
11 & Stem Family \\
12 & Endogamous Community Family \\
13 & Exogamous Community Family \\
14 & Polity IV \\
15 & Expenditure in Education \\
16 & Log GDP \\
17 & Eastern Asia \\
18 & Latin America \\
19 & Middle East \\
20 & Southern Asia \\
21 & Sub-Saharan Africa \\
22 & W. Europe \\
23 & W. Offshoots \\
\hline &
\end{tabular}


Alesina, Alberto, and Paola Giuliano. 2010. "The Power of the Family." Journal of Economic Growth 15: 93-125.

Alesina, Alberto, Paola Giuliano, and Nathan Nunn. 2013. "On the Origins of Gender Roles: Women and the Plough." Quarterly Journal of Economics.

Almond, Douglas, Lena Edlund, and Kevin Milligan. 2013. "Son Preference and the Persistence of Culture: Evidence from South and East Asian Immigrants to Canada." Population and Development Review 39: 75-95.

Barro, Robert J., and Jong Wha Lee. 1996. "International Measures of Schooling Years and Schooling Quality." American Economic Review 86: 218-223.

Barro, Robert J. and Rachel McCleary. 2008. Religion Adherence Data. http://scholar.harvard.edu/barro/publications/religionadherence-data

Bericat, Eduardo. 2012. "The European Gender Equality Index: Conceptual and Analytical Issues". Social Indicators Research 108: 1-28.

Bolt, J. 2012. “A New Database on the Origins of Institutional Development". University of Groningen Working paper. Groningen.

Bossen, Laurel, Wang Xurui, Melissa J. Brown, and Hill Gates. 2011. "Feet and Fabrication: Footbinding and Early Twentieth-Century Rural Women's Labor in Shaanxi." Modern China 37: 347-383.

Bove, Riley, and Claudia Valeggia. 2009. "Polygyny and Women's Health in sub-Saharan Africa." Social Science and Medicine 68: 21-29.

Branisa, B., Klasen, S., and Ziegler, M. 2009. "Why we should all care about social institutions related to gender inequality." Discussion paper, University of Goettingen. http://www2.vwl.wiso.unigoettingen.de/courant-papers/CRC-PEG_DP_15.pdf

Branisa, Boris, Stephan Klasen, and Maria Ziegler. 2013. “Gender Inequality in Social Institutions and Gendered Development Outcomes." World Development 45: 252-268.

Bruning, Gwennaële, and Janneke Plantenga. 1999. "Parental Leave and Equal Opportunities: Experiences in Eight European Countries." Journal of European Social Policy 9: 195-209. 
Carmichael, Sarah. 2011. "Marriage and Power: Age at First Marriage and Spousal Age Gap in Lesser Developed Countries." The History of the Family 16: 416-436.

Carmichael, Sarah and Selin Dilli. Forthcoming. "Gender Inequality in a Long Term Perspective" in Global Well-being and Development: A Long-term Perspective since 1820. Paris: OECD.

Cavalli, A. 1983. 'The Changing Role of Women: the Case of Italy'. In: Eugen Lupri (ed.) The Changing position of Women in Family and Society: A Cross-National Comparison, pp. 179-189. Leiden: E. J. Brill.

Christy, A. 1987. Sex Differences in Political participation: Processes of Change in Fourteen Nations. New York: Preager.

De Moor, Tine, and Jan Luiten Van Zanden. 2010. “Girl Power: The European Marriage Pattern and Labour Markets in the North Sea Region in the Late Medieval and Early Modern Period." Economic History Review 63: 1-33.

Dorius, Shawn F. and Glenn Firebaugh. 2010. "Trends in Global Gender Inequality." Social Forces 88: 1941-1968.

Doepke, Matthias, Michèle Tertilt, and Alessandra Voena. 2012. "The Economics and Politics of Women's Rights." Annual Review of Economics 4: 339-372.

Donno, D. and Russett, B. M. 2004. Islam, authoritarianism, and female and empowerment: What are the linkages? World Politics 56: 587-602.

Duflo, Esther. 2012. "Women Empowerment and Economic Development." Journal of Economic Literature 50: 1051-1079.

Duranton, Gilles, Andrés Rodriguez-Pose, and Richard Sandall. 2009. "Family Types and the Persistence of Regional Disparities in Europe." Economic Geography 85: 23-47.

Dyson, Tim, and Mick Moore. 1983. "On Kinship Structure, Female Autonomy, and Demographic Behavior in India." Population and Development Review 9: 35-60.

Eastin, Joshua, and Aseem Prakash. 2013. "Economic Development and Gender Equality: Is There a Gender Kuznets Curve?" World Politics 65: 156-186.

Fish, M. Steven. 2002. "Islam and Authoritarianism.” World Politics 55: 4-37.

Galasso, V., and Profeta, P. 2010. When the state mirrors the family: The design of pension systems. Netspar Discussion Papers. http://arno.uvt.nl/show.cgi?fid=106633 
Goldin, Claudia. 2006. "The Quiet Revolution That Transformed Women's Employment, Education, and Family." American Economic Review 96: 1-21.

Horrell, Sara, and Jane Humphries. 1995. “Women's Labour Force Participation and the Transition to the Male-Breadwinner Family, 1790-1865." The Economic History Review 48: 89-117.

Inglehart, Ronald, and Wayne E. Baker. 2000. "Modernization, Cultural Change, and the Persistence of Traditional Values." American Sociological Review 65: 19-51.

Inglehart, Ronald, Pippa Norris, and Christian Welzel. 2002. "Gender Equality and Democracy." Comparative Sociology 1: 321-345. International Labour Office. 2013. LABORSTA. http://laborsta.ilo.org/default.html (May 2013).

Klasen, Stephan, and Claudia Wink. 2003. “Missing Women': Revisiting the Debate." Feminist Economics 9: 263-299.

La Porta, R., F. Lopez-de-Silanes, A. Shleifer, and R. Vishny. 1999. “The Quality of Government." Journal of Law, Economics, and Organization 15: 222-279.

La Porta, Rafael, Florencio Lopez-de-Silanes, and Andrei Shleifer. 2008. "The Economic Consequences of Legal Origins." Journal of Economic Literature 46: 285-332.

Maddison, A. 2010. Statistics on World Population, GDP and Per Capita GDP, 1-2008 AD.

Mamadouh, Virginie. 1999. “A Political-cultural Map of Europe. Family Structures and the Origins of Differences Between National Political Cultures in the European Union". GeoJournal 47: 477486.

Marshall, M. G., and K. Jaggers. 2002. "Polity IV Project: Political Regime Characteristics and Transitions, 1800-2002."

Mitchell, Brian Redman. 2007. International Historical Statistics. 6th ed. Basingstoke, Hampshire, [etc.]: Palgrave Macmillan.

Murdock, George Peter. 1967. "Ethnographic Atlas: a Summary." Ethnology 6: 109-236.

Norris, P., and Inglehart, R. 2003. Rising Tide: Gender Equality and Cultural Change. New York: Cambridge University Press.

Nour, Nawal. 2006. "Health Consequences of Child Marriage in Africa." Emerging Infectious Diseases 12: 1644-1649.

Nunn, Nathan. 2012. "Culture and the Historical Process." Economic History of Developing Regions 27: S108-S126. 
Oster, Emily. 2004. "Witchcraft, Weather and Economic Growth in Renaissance Europe." Journal of Economic Perspectives 18: 215228.

Paxton, P., Green, J. and Hughes, M. 2008. Women in Parliament, 19452003: Cross-National Dataset. ICPSR ed. Ann Arbor, MI: Interuniversity Consortium for Political and Social Research [producer and distributor], doi:10.3886/ ICPSR 243402.v1

Rabe-Hesketh, Sophia, Anders Skrondal, and Andrew Pickles. 2004. "Generalized Multilevel Structural Equation Modeling." Psychometrika 69: 167-190.

Raj, Anita, Niranjan Saggurti, Donta Balaiah, and Jay G Silverman. 2009. "Prevalence of Child Marriage and Its Effect on Fertility and Fertility-control Outcomes of Young Women in India: a Crosssectional, Observational Study." The Lancet 373: 1883-1889.

Reher, David Sven. 1998. "Family Ties in Western Europe: Persistent Contrasts." Population and Development Review 24: 203-234.

Saxonberg, Steven. 2000. "Women in East European Parliaments." Journal of Democracy 11: 145-158.

Shachar, Ayelet. 2001. Multicultural Jurisdictions: Cultural Differences and Women's Rights. Contemporary Political Theory. Cambridge etc.: Cambridge University Press.

Skrondal, Anders, and Sophia Rabe-Hesketh. 2004. Generalized Latent Variable Modeling: Multilevel, Longitudinal, and Structural Equation Models. Taylor and Francis.

Schalkwyk, Johanna, and Beth Woroniuk. 1999. Russia: Gender Equality Issues and Resources in Brief. Quebec: Canadian International Development Agency.

Tabellini, Guido. 2010. "Culture and Institutions: Economic Development in the Regions of Europe." Journal of the European Economic Association 8: 677-716.

Tertilt, M. 2006. "Polygyny, Women's Rights, and Development." Journal of the European Economic Association 4: 523-530.

Todd, Emmanuel. 1985. The Explanation of Ideology Family Structures and Social Systems. Family, Sexuality and Social Relations in Past Times. Oxford: Blackwell.

- - - 1987. The Causes of Progress : Culture, Authority, and Change. Oxford; New York: B. Blackwell.

UNDP. 2011. Human Development Report 2011: Sustainability and Equity: A Better Future for All. New York: United Nations Development Programme. 
United Nations, Department of Economic and Social Affairs, Population Division (2013). World Population Prospects: The 2012 Revision, Key Findings and Advance Tables. http://esa.un.org/wpp/ExcelData/population.htm.

Wejnert, Barbara (2007). Nations, Development, and Democracy, 18002005. ICPSR20440-v1. Buffalo, NY: Barbara Wejnert, University at Buffalo-SUNY [producer]. Ann Arbor, MI: Inter-university Consortium for Political and Social Research [distributor], 200712-13. doi:10.3886/ICPSR20440.v1

Weldon, Laurel, and Mala Htun. 2012. "Sex Equality in Family Law: Historical Legacies, Feminist Activism, and Religious Power in 70 Countries." https://openknowledge.worldbank.org/handle/10986/9204.

World Bank. 2011. Gender Equality and Development World Development Report 2012. Washington. DC: The World Bank. 